Liane Esteves Daudt 1 Débora Zechmaister 1 Liliana Portal 2 Eurico Camargo Neto 2 Lúcia Mariano da Rocha Silla 1 Roberto Giugliani 3

\section{Triagem neonatal para hemoglobinopatias: um estudo piloto em Porto Alegre, Rio Grande do Sul, Brasil}

\author{
Neonatal screening for hemoglobinopathies: \\ a pilot study in Porto Alegre, \\ Rio Grande do Sul, Brazil
}

1 Serviço de Hematologia eTransplante de Medula Óssea, Hospital de Clínicas de Porto Al egre, Universidade Federal do Rio Grande do Sul. Rua Ramiro Barcel os 2350, sala 2235, Porto Al egre, RS 90035-003, Brasil. Idaudt@hcpa.ufrgs.br 2 Laboratório Nobel-RIE, Centro de Triagem Neonatal Avenida Ipiranga 5000, Porto Al egre, RS 90610-000, Brasil. 3 Serviço de Genética Médica, Hospital de Clínicas de Porto Al egre, Universidade Federal do Rio Grande do Sul. Rua Ramiro Barcel os 2350, Porto Al egre, RS 90035-003, Brasil.

\begin{abstract}
This study was conducted to establish the frequency of hemogl obinopathies among newborns undergoing screening tests for metabolic diseases at the University Hospital (Hospital de Clínicas) in Porto Al egre, Rio Grande do Sul, Brazil. Testing for abnormal hemoglobins was performed by isoelectric focusing el ectrophoresis on agarose gel with blood obtained by heel stick and applied to filter paper. For confirmatory testing of abnormal neonatal screening, a venopuncture blood sample was obtained from the infant and parents and then submitted to hemoglobin electrophoresi s on cellulose acetate at pH 8.6 and citrate agar at $\mathrm{pH}$ 6.2. A total of 1,615 subjects were studied: 20 samples showed the Hb S pattern and six samples showed Hb C. Thus, frequency of the sickle cell gene was $1.2 \%$ and that of the $\mathrm{Hb} \mathrm{C}$ gene was $0.4 \%$, regardless of race or origin. These data suggest that the inclusion of universal neonatal screening for hemoglobinopathies in the ongoing projects for the detection of phenylketonuria and congenital hypothyroidism has many advantages and should be consi dered in heal th programs.
\end{abstract}

Key words Sickle Cell Anemia; Hemoglobinopathies; Neonatal Screening; Child Health

Resumo Este estudo, tem como o objetivo determinar a freqüência das hemogl obi nopatias em neonatos, que realizaram a col eta para o Teste de Triagem Neonatal para Distúrbios Metabólicos no Hospital de Clíni cas de Porto Al egre. O método utilizado para a determinação das variantes da hemoglobina, foi el etroforese por focalização isoelétrica em amostra de sangue total, coletadas em papel filtro por punção do calcanhar. Para confirmação diagnóstica dos casos alterados, foram real izadas el etroforeses das hemogl obi nas em acetato de cel ul ose com pH 8,6 e em citrato deágar com pH 6,2, em amostra de sangue total dos neonatos e dos seus progenitores. Foram analisados, 1.615 indi víduos, e identificada a presença da hemoglobina S em 20 amostras e da hemogl obina $\mathrm{C}$ em seis amostras. Esses val ores, correspondem a uma freqüência de 1,2\% para o gene da anemi a falci forme e $0,4 \%$ para o gene da doença de hemogl obina $C$, independente da raça ou ascendência. Esses dados, sugerem que a inclusão da triagem neonatal universal para hemogl obinopatias nos projetos já implementados para fenilcetonúria e hipotireoi di smo congênito, apresenta vantagens e deve ser considerada pel os programas de saúde.

Palavras-chave Anemia Fal ciforme; Hemoglobinopatias; Triagem Neonatal; Saúde Infanti l 


\section{Introdução}

Historicamente, a anemia falciforme, expressão clínica dos homozigotos do gene da hemoglobina S e forma mais conhecida das hemoglobinopatias, tem sido associada com alta morbidade e mortalidade na infância, devido a sepse bacteriana, crise de seqüestração esplênica e síndrome torácica aguda (Shaffer et al., 1996). O tratamento médico de suporte pode reduzir esses índices (Embury, 1995). Em 1986, um estudo clínico randomizado duplo-cego, demonstrou que o uso profilático de penicilina, reduz a morbidade e mortalidade de infecções bacterianas em crianças abaixo de cinco anos (Gaston et al., 1986). Frente a esses dados, que sugerem a melhora da sobrevida com o acompanhamento médico e educacional, surgiram vários estudos mostrando a necessi dade do diagnóstico precoce, podendo ser realizado mesmo no período neonatal (Diaz-Barrios, 1989; Garrick et al., 1973; Gill et al., 1989).

Apesar da incidência de anemia falciforme ser mais comum em pessoas da raça negra, estudos populacionais têm demonstrado a presença de hemoglobina $\mathrm{S}$ em pessoas descendentes de populações do Mediterrâneo, Caribe, América Central e do Sul, Arábia e Índia. 0 Brasil apresenta uma população com diferentes origens raciais e com diversificados graus de miscigenação (Azevedo, 1980); assim, para um programa ser eficiente, todos os recém nascidos deveriam ser testados independentemente do grupo étnico (Angastiniotis \& Modell, 1998).

O maior estudo de prevalência e distribuição de hemoglobinopatias realizado no Brasil, analisou amostras de 55.217 indivíduos, em quarenta cidades, com idades entre um mês e noventa anos, provenientes de centros de saúde, escolas e bancos de sangue. Neste estudo, $3,08 \%$ dos indivíduos tinham hemoglobinas anormais desdobradas em variantes moleculares $(2,49 \%)$, talassemias $(0,53 \%)$ e alterações induzidas pela formação de meta-hemoglobinemias $(0,06 \%)$. A condição $\mathrm{HbAS}$ foi a mais prevalente, com 1.038 casos $(60,95 \%)$ do total de 1.703 portadores; as talassemias alfa e beta somaram 265 casos (15,56\%); a condi ção HbAC foi detectada em 243 (14,27\%) e as formas mais raras, em 156 casos (9,27\%). A freqüência de $\mathrm{HbSS}$ na população total foi de $0,04 \%$. Entre os vinte portadores com HbSS identificados e comprovados clinicamente, 18 pertenciam ao grupo negróide $(0,22 \%)$ e dois ao grupo caucasóide (Naoum et al., 1987).

Alguns estudos procuraram estimar a prevalência de hemoglobinopatias no Sul do Bra- sil. Pedrollo et al. (1990), estudaram 559 amostras de sangue do cordão umbilical e determinaram uma freqüência de 3,7\% de Hb Bart's (alfa-talassemia) na população geral (5,4\% em negrose 2,5\% em brancos). Salzano et al. (1968), através de exames real izados na rotina de um laboratório público de Porto Alegre, encontraram uma freqüência de $\mathrm{HbAS}$ de $6.8 \%, \mathrm{HbAC}$ de $1 \%$, $\mathrm{HbSC}$ de $0,1 \%$ e HbSS de $0,1 \%$, em uma população negróide formada em sua maioria por adultos. Entretanto, considerando apenas as crianças menores de nove anos, a doença falciforme foi encontrada em 3,5\% dos indivíduos (Salzano \& Tondo, 1962; Salzano et al., 1968). A freqüência de heterozigotos para betatalassemia foi estimada em 1,1\%, conforme o estudo realizado em 704 caucasianos adultos (Freitas \& Rocha, 1983).

Entretanto, não se conhece a freqüência das hemoglobinopatias em recém-nascidos nesta região, o que permitiria a identificação real da prevalência antes da ocorrência de manifestações clínicas em uma amostra não selecionada.

O objetivo deste estudo, é estabelecer a prevalência das hemoglobinopatias nos recémnascidos do Hospital de Clínicas de Porto Alegre (HCPA), que já participam do Programa de Triagem Neonatal para hipotireoidismo congênito e fenilcetonúria, independente da raça ou ascendência, e avaliar o benefício da adição da triagem para hemoglobinopatias ao programa em curso.

\section{Metodologia}

Foram analisados, 1.615 amostras consecutivas dos neonatos que participaram da coleta do “Teste do Pezinho - Triagem Neonatal de Distúrbios Metabólicos", realizada no Hospital de Clínicas de Porto Alegre (HCPA), durante o período de 18 de março a 30 de outubro de 1999. As variáveis avaliadas durante a coleta foram: data de nascimento, data da coleta, data da realização da eletroforese, sexo, cidade e endereço da residência materna e peso de nascimento. Os pais foram classificados em brancos, negros, mistos, indígenas e orientais levando em consideração a cor da pele e ol hos, espessura dos lábios e características do cabelo (Azevedo, 1980; Sousa, 1982).

Durante o período do estudo, o número de nascimentos no HCPA, foi de 3.024 nativivos. Assim, aproximadamente $55 \%$ dos nascidos no hospital, realizaram o Teste de Triagem Neonatal para Distúrbios Metabólicos.

A técnica utilizada para a pesquisa de hemoglobinopatias como triagem neonatal, foi a 
eletroforese de hemoglobina por focalização isoelétrica em gel de agarose (WALLAC-ISOLAB Akron/Estados Unidos), com amostras de sangue total coletadas em papel filtro, a partir de punção do calcanhar, armazenadas e refrigeradas a uma temperatura de $8 \circ \mathrm{C}$.

Os casos classificados como alterados, foram os que apresentaram banda S ou C, banda na posição da $\mathrm{HbA}_{2}$ pela proximidade com a $\mathrm{HbC}$ ou outra banda que não $\mathrm{HbA}$ ou $\mathrm{HbF}$.

A confirmação diagnóstica dos casos alterados na focalização isoelétrica, foi realizada por meio das eletroforeses das hemoglobinas em acetato de celulose com pH 8,6 e em citrato de ágar com pH 6,2 do recém-nascido e dos pais. A análise dos pais, foi realizada com o intuito de identificar os pacientes com risco de serem homozigotos antes da normalização da concentração da Hb Fetal, que ocorre após o sexto mês de vida.

Por definição, os pacientes heterozigotos para determinada variante, devem apresentar concentração da hemoglobina alterada inferior a $45 \%$, geralmente variando entre 30 a $40 \%$, e predomínio da HbA (Naoum \& Domingos, 1997; Serjeant, 1999), enquanto que os pacientes homozigotos para as variantes $\mathrm{HbS}$ e $\mathrm{HbC}$, apresentam concentrações superiores à $90 \%$ e ausência de HbA.

\section{Análise estatística}

Foram utilizadas estatísticas descritivas para a comparação entre as variáveis, e utilizados o teste do Qui-quadrado, o teste exato de Fisher ou o teste " $\mathrm{t}$ " com alfa crítico $\leq 0,05$. Os dados foram armazenados em planilha do programa Microsoft Excel 7.0 para Windows 98, transferidos para banco de dados dBase e posteriormente analisados no programa SPSS 8.0 (SPSS Incorporation, 1997).

\section{Considerações éticas}

Os benefícios da identificação neonatal em termos de reduzir a morbidade e a mortalidade de crianças portadoras de hemoglobinopatias, claramente superam os riscos da triagem. O procedimento de coleta por punção de calcâneo é considerado seguro e pouco doloroso, e inclui pesquisa de outras doenças genéticas já consagradas. Considerando que, o delineamento deste estudo utilizou o material coletado para o Teste de Triagem de Distúrbios Metabólicos, tomou-se por base a resolução normativa 02/97, da Comissão de Pesquisa e Ética em Saúde do Grupo de Pesquisa e Pós-Graduação do HCPA, que regulamenta a Utilização de Mate- rial Biológico Descartado em Projeto de Pesquisa. Assim, na necessidade de informar o resultado anormal e possibilitar o encaminhamento precoce deste paciente, foi utilizado o Termo de Compromisso para a Utilização de Dados (Resolução 1/97), a fim de garantir a privacidade dos dados coletados conforme as disposições "c" e "d" dessa resolução (Goldin, 1997), e aceita pelo Comitê de Ética do hospital.

\section{Resultados}

Durante o período do estudo, foram coletadas 1.616 amostras, tendo ocorrido uma perda, sendo a eletroforese por focalização isoelétrica realizada em 1.615 recém-nascidos. Ao total, 98,8\% dos indivíduos estudados moravam em Porto Alegre ou na área metropolitana, sendo $48,8 \%$ do sexo feminino e $50,2 \%$ do sexo masculino. O peso médio de nascimento foi de $3.175 \mathrm{~g}$ (DP $\pm 616 \mathrm{~g}$ ), com variação de $630 \mathrm{~g}$ a $4.950 \mathrm{~g}$.

A distribuição das raças dos pais, dado disponível em 208 casos, avaliada durante o primeiro mês do estudo, foi a seguinte: entre os pais $66,2 \%$ de brancos, $23,2 \%$ de negros e $10,6 \%$ de mistos; entre as mães $69,2 \%$ de brancas, $22,6 \%$ de negras e $8,2 \%$ de mistas. Não foram encontrados índios ou orientais na amostra estudada.

O tempo médio decorrente entre o nascimento e a coleta do teste de triagem, foi de 11,7 dias (DP $\pm 11,1$ dias) com faixa de variação de 3 a 116 dias. A eletroforese foi realizada, em média, 22 dias após a coleta com desvio padrão de dez dias.

A Tabela 1 resume as características da população estudada.

Das 1.615 amostras, 39 foram classificadas como alteradas. Duas outras foram acrescidas a estas, pois, apesar de normais, eram nascimentos gemelares de pacientes com alteração. Assim, 41 crianças foram chamadas para repetir a el etroforese em acetato de celulose e em citrato de ágar.

Todos esses recém-nascidos, foram procedentes da região metropolitana e da cidade de Porto Alegre. Em comparação com a amostra total, não existiram diferenças entre a distribuição do sexo, peso de nascimento e tempo entre o nascimento e a coleta e a realização da eletroforese por focalização isoelétrica (Tabela 2). Entretanto, a distribuição da raça dos pais, apresentou um número maior de indivíduos negros e mistos ( $p<0.05)$.

A média de idade em que os indivíduos com triagem alterada realizaram el etroforese para confirmação diagnóstica, foi de 98,7 dias 
Tabela 1

Características da amostra estudada.

\begin{tabular}{|c|c|c|c|}
\hline & $\mathrm{n}$ & $\%$ & \\
\hline \multicolumn{4}{|l|}{ Localidade } \\
\hline Porto Alegre & $1.042 / 1.606$ & 64,9 & \\
\hline Região Metropolitana & $546 / 1.606$ & 33,9 & \\
\hline Outras localidades & $18 / 1.606$ & 1,2 & \\
\hline \multicolumn{4}{|l|}{ Sexo } \\
\hline Feminino & $773 / 1.585$ & 47,8 & \\
\hline Masculino & $812 / 1.585$ & 50,2 & $p>0,05$ \\
\hline Peso de nascimento $(\mathrm{g})$ & 1.597 & & \\
\hline Média (desvio padrão)* & $3.175( \pm 616)$ & & \\
\hline Variação & $630-4.950$ & & \\
\hline \multicolumn{4}{|l|}{ Cor do pai } \\
\hline Branca & $137 / 207$ & 66,2 & \\
\hline Negra & $48 / 207$ & 23,2 & \\
\hline Mista & $22 / 207$ & 10,6 & \\
\hline Cor da mãe & & & $p>0,05$ \\
\hline Branca & $144 / 208$ & 69,2 & \\
\hline Negra & $47 / 208$ & 22,6 & \\
\hline Mista & $17 / 208$ & 8,2 & \\
\hline
\end{tabular}

$\mathrm{n}$ = número de casos/número total de casos avaliados em determinada variável. * a variável peso de nascimento está apresentada em gramas e não em porcentagem.
$20 \%$. Entretanto, nos outros cinco casos não é possível determinar o fenótipo.

As outras al terações encontradas na triagem neonatal foram: duas amostras com HbBarts em concentração inferior a $2 \%$; uma amostra com $\mathrm{HbF}$ variante, esta foi confirmada por biologia molecular como variante da cadeia gama, porém não retornou para reconsulta; uma banda desconhecida com migração próxima a $\mathrm{HbS}$ que não ocorreu na eletroforese em celulose/ ágar, assim como os pais foram normais e nove pela presença de $\mathrm{HbA}_{2}$. Entre os neonatos que apresentaram $\mathrm{HbA}_{2}$, sete retornaram para reconsulta, sendo que em todos, a eletroforese em celulose/ágar foi normal, assim como em seus pais. Dessas crianças, quatro tinham recebido transfusões sangüíneas previamente à coleta: duas por incompatibilidade Rh, uma por prematuridade e outra por hiperbilirribinemia neonatal severa; em uma, a amostra foi coletada com 50 dias de vida e em outras duas, com 14 e 12 dias de vida. Apenas um recém-nascido, chamado por apresentar $\mathrm{Hb}$ Barts, retornou para consulta e seus exames foram normais.

\section{Discussão}

O principal objetivo deste estudo, foi determinar a freqüência das hemogl obinopatias entre os recém-nascidos que se submeteram à Triagem Neonatal para Distúrbios Metabólicos. O fato de que apenas em $55 \%$ dos nascidos no HCPA, durante o período da análise tenham coletado o teste, é o principal argumento de vários autores para a realização da triagem de hemoglobinopatias em coleta de cordão umbilical (Bandeira et al., 1999; Lobel et al., 1989; Mack, 1989; Pantaleão et al., 1993). Entretanto, o diagnóstico dos distúrbios metabólicos, principalmente a fenilcetonúria, não é possível no momento do parto, o que tornaria necessária a realização de duas coletas em momentos diferentes, para completar os exames de triagem neonatal. A experiência em outros estudos, mostra que a educação e a orientação sobre as vantagens dos exames para pais e profissionais de saúde, aumentam a procura pelos testes de triagem (Compri et al., 1996; Filho et al., 1988; Grover, 1989; Shafer et al., 1996).

Entre os 41 indivíduos com resultados alterados, 13 não retornaram para consulta. Desses, oito não buscaram o resultado da triagem conforme a rotina do hospital. Os demais, mesmo sendo informados do resultado, não retornaram. Esses indivíduos não foram localizados nos endereços que forneceram. Todos os pacientes que consultaram e que foram orienta- 
Características das amostras alteradas e comparação com a amostra total.

\begin{tabular}{|c|c|c|c|c|c|}
\hline & $n=41 \S$ & $\begin{array}{c}\text { Cas } \\
n\end{array}$ & $\begin{array}{l}\text { terados } \\
\%\end{array}$ & $\begin{array}{c}\text { População geral } \\
\%\end{array}$ & \\
\hline \multicolumn{6}{|l|}{ Localidade } \\
\hline Porto Alegre & & 20 & 48,8 & 64,9 & \\
\hline Região Metropolitana & & 21 & 51,2 & 33,9 & \\
\hline Viamão & & 10 & 24,4 & 15,7 & \\
\hline Canoas & & 5 & 12,2 & 6,7 & \\
\hline Outras localidades & & 0 & & 1,2 & $p>0,05$ \\
\hline Sexo & $n=40 \S$ & & & & \\
\hline Feminino & & 19 & 46,6 & 47,8 & \\
\hline Masculino & & 22 & 53,6 & 50,2 & $p>0,05$ \\
\hline Peso de nascimento (g) & & 41 & & & \\
\hline Média (desvio padrão)* & & $3.154( \pm 753)$ & & $3.175( \pm 616)$ & \\
\hline Variação & & $1.400-4600$ & & $630-4.950$ & \\
\hline Cor do pai & $\mathrm{n}=31 \S$ & & & & \\
\hline Branca & & 10 & 32,3 & 66,2 & \\
\hline Negra & & 12 & 38,7 & 23,2 & \\
\hline Mista & & 9 & 29 & 10,6 & $p<0,05$ \\
\hline Cor da mãe & $n=31 \S$ & & & & \\
\hline Branca & & 16 & 51,6 & 69,2 & \\
\hline Negra & & 11 & 35,5 & 22,6 & \\
\hline Mista & & 4 & 12,9 & 8,2 & $p>0,05$ \\
\hline
\end{tabular}

* a variável peso de nascimento está apresentada em gramas e não em porcentagem.

$\S=$ número total de casos observados.

dos após receber os resultados, retornaram para a realização dos exames confirmatórios, não havendo nenhuma recusa. Novamente, a educação e orientação parece ser fundamental para o sucesso da triagem neonatal (Rowley, 1989).

Historicamente, a anemia falciforme e a doença da hemoglobina C têm origem na África, onde persistem as maiores prevalências. A sua presença nas Américas é decorrente da imigração dos indivíduos pertencentes à raça negra, originários desse continente (Flint et al., 1993). Neste estudo, a variável cor foi avaliada de forma subjetiva, considerando cor da pele e características faciais e do cabelo. De fato, apenas os pacientes que consultaram por apresentar resultados alterados, e um pequeno grupo da população geral em que foi possível avaliar esta informação na presença dos pais, foram classificados. Esta análise, demonstra um número maior de negros e mistos, equivalente a pardos e pretos, em relação à Pesquisa Nacional por Amostra de Domicílios de 1996 (IBGE, 1996), onde a distribuição da população por cor na área metropolitana de Porto Alegre é de $86,05 \%$ de brancos, $5,75 \%$ de pretos e $7,72 \%$ de pardos. Essa diferença, pode ter ocorrido devido à uma possível seleção da população que consulta no HCPA, onde predomina o atendimento pelo Sistema Ú nico de Saúde de indivíduos sócio-economicamente menos favorecidos, classe em que o número de pretos e pardos é maior.

A miscigenação da nossa população é significativa e progressiva, e a classificação por cor da pele e outras características, não pode ser atualmente utilizada como única mensuração de raça (Pantaleão et al., 1993; Salzano et al., 1968) Entretanto, o fenótipo das hemoglobinopatias S ou C, permite afirmar que existe ascendência africana. Neste estudo, apenas o grupo de pais dos casos AS e AC, demonstraram diferença estatística entre a variável cor, com predomínio de indivíduos classificados como mistos. Este dado, confere com a presença de um número maior de pais AS (Tabela 3). Entre os casais avaliados, apenas seis casais 
Características fenotípicas e origem do Alelo - Hemoglobina S e Hemoglobina C.

\begin{tabular}{|c|c|c|c|c|c|c|c|c|}
\hline & Cidade & Sexo & Cor do pai & Cor da mãe & $\mathrm{Hx} \mathrm{Hbp}$ & Interc. Neo & Fenótipo & Herança \\
\hline 1 & Porto Alegre & $\mathrm{F}$ & $M$ & B & - & - & AS & Mãe \\
\hline 2 & Viamão & M & $\mathrm{N}$ & $\mathrm{N}$ & - & - & AS & Pai \\
\hline 3 & Viamão & $\mathrm{M}$ & $\mathrm{N}$ & $\mathrm{N}$ & + & ict/foto & $\mathrm{FS}^{*}$ & \\
\hline 4 & Porto Alegre & M & $M$ & B & - & - & AS & Pai \\
\hline 5 & Porto Alegre & $\mathrm{F}$ & M & M & - & - & AS & Pai \\
\hline 6 & Porto Alegre & M & & & & & $\mathrm{FS}^{*}$ & \\
\hline 7 & Canoas & $\mathrm{F}$ & B & B & - & - & AS & Pai \\
\hline 8 & Porto Alegre & $\mathrm{F}$ & & & & & $\mathrm{FS}^{*}$ & \\
\hline 9 & Canoas & $\mathrm{F}$ & $M$ & B & - & - & AS & Pai \\
\hline 10 & Porto Alegre & $\mathrm{F}$ & $N$ & $\mathrm{~N}$ & + & - & AS & Mãe \\
\hline 11 & Porto Alegre & M & $M$ & B & - & ict & AS & Pai \\
\hline 12 & Porto Alegre & M & & & & & $\mathrm{FS}^{*}$ & \\
\hline 13 & Porto Alegre & $\mathrm{F}$ & & & & & $\mathrm{AFS}^{*}$ & \\
\hline 14 & Porto Alegre & $\mathrm{F}$ & $\mathrm{N}$ & $\mathrm{N}$ & - & - & AS & Pai \\
\hline 15 & Porto Alegre & M & $\mathrm{M}$ & $\mathrm{N}$ & - & ict & AS & Mãe \\
\hline 16 & Viamão & $\mathrm{F}$ & $\mathrm{M}$ & M & - & - & AS & Pai \\
\hline 17 & Gravataí & M & $\mathrm{N}$ & B & - & ict & AS & Pai \\
\hline 18 & Viamão & $\mathrm{F}$ & $\mathrm{N}$ & $\mathrm{N}$ & - & - & AS & Pai \\
\hline 19 & Viamão & $M$ & $\mathrm{~N}$ & B & + & - & AS & Mãe \\
\hline 20 & Eldorado do Sul & M & B & B & - & - & AS & Mãe \\
\hline 1 & Porto Alegre & $\mathrm{F}$ & B & $\mathrm{N}$ & - & - & $A C$ & Mãe \\
\hline 2 & Porto Alegre & $\mathrm{F}$ & $\mathrm{M}$ & B & - & - & $A F C^{*}$ & \\
\hline 3 & Alvorada & M & $B$ & B & - & - & $A C$ & Mãe \\
\hline 4 & Viamão & M & & & & & $\mathrm{FC}^{*}$ & \\
\hline 5 & Canoas & $M$ & & & & & $A F C^{*}$ & \\
\hline 6 & Canoas & $\mathrm{F}$ & $\mathrm{N}$ & $\mathrm{N}$ & - & - & $\mathrm{AC}$ & Pai \\
\hline
\end{tabular}

Sexo: $M=$ masculino, $F=$ feminino; cor: $B=$ branco, $N=$ negro, $M=$ misto; $\mathrm{Hx} \mathrm{Hbp}=$ história familiar de hemoglobinopatias; Interc $\mathrm{Neo}=$ intercorrências durante o período neonatal; ict = icterícia neotatal; foto $=$ fototerapia + + = positivo; - = negativo .

* Resultados da eletroforese por Focalização Isoelétrica sem confirmação em citrato/ágar.

eram concordantes na raça negra, cinco casais eram brancos e mistos, três brancos e negros, dois concordantes em mistos, um misto e negro e três casais classificados como brancos geraram filhos heterozigotos para hemoglobinopatia S ou C. Esta é a característica que demonstra a dinâmica que o gene apresenta na população, tornando a herança não exclusiva da raça negra e justificando a triagem universal. Assim, podemos dizer que $1,6 \%$ da população estudada herdou um gene originário do continente africano.

As amostras de sangue coletadas em papel filtro, permitem a associação da triagem para hemoglobinopatias com os demais testes, têm fácil transporte e armazenamento, ainda que diminuam a estabilidade das hemoglobinas (Papadea et al., 1994). Desde 1973, quando Garrick et al. (1973) descreveram o método de he- molisado para a eluição da hemoglobina do papel filtro e a possibilidade de realizar a eletroforese em acetato de celulose e citrato de ágar para a triagem neonatal, vários grupos consideram este método adequado para a coleta e armazenamento dos testes de neonatais (Githens et al., 1990; Grover et al., 1983; Schedlbauer \& Pass, 1989; Shafer et al., 1996). Kinney et al. (1989) compararam amostras de sangue de cordão, simultaneamente coletadas em papel filtro e em tubos com heparina com até 15 dias, e demonstraram que é possível identificar claramente as bandas de $\mathrm{HbF}, \mathrm{HbA}$, $\mathrm{HbS}$ e $\mathrm{HbC}$ nos dois métodos, embora a resolução fosse melhor nas amostras dos tubos. A introdução das técnicas com maior sensibilidade, como a eletroforese por focalização isoelétrica e a cromatografia líquida de alta resolução, além de possibilitarem a extração de DNA para 
a análise genotípica, consolidaram a coleta em papel filtro (Huisman, 1989; Kleman et al., 1989; Kutlar et al., 1990; Papadea et al., 1994; Wajcman et al., 1993).

Neste estudo, só foram utilizadas amostras de sangue em papel filtro, coletadas rotineiramente para a Triagem de Distúrbios Metabólicos do HCPA. Em todos os casos, houve quantidade suficiente para a realização da eletroforese, possi bilitando a visualização adequada da $\mathrm{HbF}, \mathrm{HbA}$ e de outras variantes. O armazenamento, em geladeira a 4-80 C, e o transporte ao laboratório, onde foram realizados os testes, foram simplificados pela coleta em papel filtro, tendo apenas uma amostra sido perdida após a identificação.

A eletroforese por focalização isoelétrica, é considerada um método conveniente para detectar variantes da hemoglobina, mesmo quando em concentrações baixas como ocorre no período neonatal, além de possibilitar a distinção entre homozigotos e heterozigotos (Beuzard et al., 1981; Dubart et al., 1980). Quando comparado com a eletroforese em acetato de celulose, ela se mostrou superior, pois além da melhor resolução, possibilita a separação de $\mathrm{H}$ bS da $\mathrm{HbF}$ de forma mais evidente (Kleman et al., 1989). Em termos de custo, apesar do equipamento para análise por a focalização isoelétrica ser mais caro, os reagentes têm preço equivalente e é possível realizar 72 testes a cada seis horas.

Neste estudo, todas as amostras foram triadas pela focalização isoelétrica, tendo como método de confirmação a eletroforese em acetato de celulose e em citrato de ágar em novas amostras. Esse método, permitiu a identificação de 26 portadores do gene da HbS e HbC, sendo que houve concordância em todas as amostras em que foi possível a recoleta.

Segundo um estudo realizado por Pedrollo et al. (1990), a freqüência de Hb Barts (alfa-talassemia) na população geral de Porto Alegre, é de 3,7\% (5,4\% em negros e 2,5\% em brancos). Entretanto, das 1.615 amostras que analisamos, apenas em duas se identificou a presença de HbBarts (0,12\%). Essa freqüência, muito inferior à encontrada previamente, provavelmente se deve à técnica utilizada.

A falha em detectar bandas rápidas, característica da HbBarts, já foi documentada como conseqüência do armazenamento em papel filtro. Neste meio, as hemoglobinas perdem sua estabilidade devido à oxidação do ferro da fração heme e à ação de resíduos de glutamina e asparagina na molécula protéica. Este efeito é progressivo em relação ao tempo da coleta até a realização da eletroforese (Kinney et al., 1989; Kutlar et al., 1990). A média de tempo entre a coleta e a realização da eletroforese por focalização isoelétrica, foi de 22 dias neste estudo e esse período certamente colaborou para a baixa sensibilidade em detectar a $\mathrm{HbBarts}$. Entretanto, até o momento, não existem evidências que sugiram que a identificação precoce da atalassemia tenha impacto na saúde dos recémnascidos (Kinney et al., 1989).

Salzano et al. (1968), através de exames realizados na rotina de um laboratório público de Porto Alegre, encontraram uma freqüência de $\mathrm{HbAS}$ de $6.8 \%$, $\mathrm{HbAC}$ de $1 \%$, HbSC de $0,1 \%$ e $\mathrm{HbSS}$ de $0,1 \%$ em uma população negróide formada em sua mai oria por adultos. Entretanto, considerando apenas as crianças menores de nove anos, o traço falciforme foi encontrado em 3,5\% dos indivíduos (Salzano et al., 1968; Tondo e Salzano, 1962). A freqüência encontrada neste estudo para portadores do gene da Doença Falciforme, foi de 1,2\% e para portadores do gene da Doença da Hemoglobina $C$, foi de 0,4\%. Assim, 1,6\% da amostra estudada, apresentou uma variante da hemoglobina que pode acarretar uma doença em que a intervenção precoce reduz suas conseqüências.

Esses dados sugerem que a inclusão da triagem neonatal para hemoglobinopatias nos projetos já implementados para fenilcetonúria e hipotireoidismo congênito, apresenta muitas vantagens e deve ser considerado pelos programas de saúde. 


\section{Referências}

ANGASTINIOTIS, M.\&. MODELL, B., 1998. Global epidemiology of hemoglobin disorders. Annals of the New York Academy of Sciences, 850:251-269.

AZEVEDO, E. S., 1980. Subgroup studies of black admixture within a mixed population of Bahia, Brazil. Annals of Human Genetics, 44:55-60.

BANDEIRA, F. M. G. C.; LEAL, M. C.; SOUZA, R. R.; FURTADO, V. C.; GOMES, Y. M. \& MARQUES, N. M., 1999. Características de recém-nascidos portadores de hemoglobina $\mathrm{S}$ detectados através de triagem em sangue de cordão. Jornal de Pediatria, 75:167-171.

BEUZARD, Y.; GALACTEROS, F.; BRACONNIER, F.; DUBART, A.; CHEN-MAROTEL, J.; CABURI-MARTIN, J.; MONPLAISIR, N.; SELLAYE, M.; SAINT MARTIN, C.; SEYTOR, S.; BASSET, P. \& ROSA, J., 1981. Isoeletric focusing of human hemoglobins. Advances in Hemoglobin Analysis, 60:177-195.

COMPRI, M. B.; POLIMENO, N. C.; STELLA, M. B. \& RAMALHO, A. S., 1996. Programa comunitário de hemoglobinopatias hereditárias em população estudantil brasileira. Revista de Saúde Pública, 30:187-195.

DIAZ-BARRIOS, V, 1989. New York's experience. Pediatrics, 83(Sup. 2):872-875.

DUBART, A.; GOOSSENS, M.; BEUZARD, Y.; MONPLAISIR, N.; TESTA, U.; BASSET, P. \& ROSA J., 1980. Prenatal diagnosis of hemoglobinopathies: Comparison of the results obtained by isoelectric focusing of hemoglobins and by chromatography of radioactive globin chains. Blood, 56:1092-1099.

EMBURY, S. H., 1995. Advances in the prenatal and molecular diagnisis of the hemoglobinopathies and thalassemias. Hemoglobin, 19:237-261.

FILHO, F. A.; NAOUM, P. C.; MOREIRA, H. W. \& ANGULO, I. L., 1988. Variabilidade polimórfica de hemoglobinas humanas anormais em indivíduos das cidades de Barretos e Colina, São Paulo, Brasil. Revista Brasileira de Patologia Clínica, 24:3239.

FLINT, J.; HARDING, R. M.; BOYCE, A. J. \& CLEGG, J. B., 1993. The population genetics of haemoglobinopathies. Baillieres Clinical Haematology, 6 : 215-262.

FREITAS, E. M. \& ROCHA, F. J., 1983. Detection of Beta-Thalassemia Heterozygotes among caucasians from Porto Alegre, RS, Brazil. Revista Brasileira de Genética, 6:185-188.

GARRICK, M. D.; DEMBURE, P. \& GUTHRIE, R., 1973. Sickle cell anemia and other hemoglobinopathies. Procedures and strategy for screening employing spots of blood on filter paper as specimens. New England Journal of Medicine, 288:1265-1268.

GASTON, M. H.; VERTER, J. I.; WOODS, G.; PEGELOW, C.; KELLEHER, J.; PRESBURY, G.; ZARKOWSKY, H.; VICHINSKY, E.; IYER, R.; LOBEL, J. S.; DIAMOND, S.; HOLBROOK C. T.; GILL, F. M.; RITCHEY K. \& FALLETTA, J. M., 1986. Prophylaxis with oral penicillin in children with sickle cell anemia. A randomized trial. New England Journal of Medicine, 314:1593-1599.

GILL, F. M.; BROWN, A.; GALLAGHER, D.; DIAMOND, S.; GOINS, E.; GROVER, R.; LUBIN, B.; MOORE, G. \& GASTON, M. H., 1989. Newborn experience in the cooperative study of sickle cell disease. Pediatrics, 83(Sup. 2):827-829.

GITHENS, J. H.; LANE, P. A.; MCCURDY, R. S; HOUSTON, M. L.; MCKINNA, J. D. \& COLE, D. M., 1990. Newborn screening for hemoglobinopathies in Colorado. The first 10 years. American Journal of Diseases of Children, 144:466-470.

GOLDIN, J. R., 1997. Utilização de Material Biológico Descartado em Proj eto de Pesquisa. Pesquisa em Saúde: Leis, Normas e Diretrizes. 3a Ed. Porto Alegre: Hospital de Clínicas de Porto Alegre.

GROVER, R., 1989. Newborn screening in New York City. Pediatrics, 83(Sup. 2):819-822.

GROVER, R.; SHAHIDI, S.; FISHER, B.; GOLDBERG, D. \&WETHERS, D., 1983. Current sickle cell screening program for newborns in New York City, 19791980. American Journal of Public Health, 73:249252.

HUISMAN, T. H. J., 1989. Usefulness of cation exchange high performace liquid chromatography as a testing procedure. Pediatrics, 83(Sup. 2):849851

IBGE (Fundação Instituto Brasileiro de Geografia e Estatística), 1996. Pesquisa Nacional por Amostra de Domicílios. 2 fevereiro 2000 \ttp:// www.ibge. gov.br>.

KINNEY, T. R.; SAWTSCHENKO, M.; WHORTON, M.; SHEARIN, J.; STINE, C.; HOFMAN, L.; SAFKO, R.; VITAGLIONE, T. \& KAUFMAN, R. E., 1989. Techniques' comparison and report of the North Carolina Experience. Pediatrics, 83(Sup. 2):843-848.

KLEMAN, K. M .; VICHINSKY, E. \& LUBIN, B. H., 1989. Experience with newborn screening using isoelectric focusing. Pediatrics, 83(Sup. 2):852-854.

KUTLAR, A.; OZCAN, O.; BRISCO, J. T.; ANSLEY, M. C. \& HUISMAN, T. H. J., 1990. The detection of hemoglobin variants by isoelectrofocusing using EDTA-Collected and filter paper-dried cord blood specimens. American Journal of Clinical Pathology, 94:199-202

LOBEL, J. S.; CAMERON, B. F.; JOHNSON, E.; SMITH, D. \& KALINYAK, K., 1989. Value of screening umbilical cord blood for hemoglobinopathy. Pediatrics, 83(Sup. 2):823-826.

MACK, A. K., 1989. Florida's experience with newborn screening. Pediatrics, 83(Sup. 2):861-863.

NAOUM, P. C.; ALVAREZ, F.; DOMINGOS, C. R. B.; FERRARI, F.; MOREIRA, H. W.; SAM PAIO, Z. A. MAZIEIRO, P. A. \& CASTILHO, E. M., 1987. Hemoglobinas anormais no Brasil. Prevalência e distribuição geográfica. Revista Brasileira de Patologia Clínica, 23:68-79.

NAOU M, P. C. \& DOMINGOS, C. R. B., 1997. Técnicas laboratoriais para identificação das hemoglobinas normais e anormais. In: Hemoglobinopatiase Talassemias (P. C. Naoum \& C. R. B. Domingos, org.), pp. 144-171, 1a Ed., São Paulo: Sarvier.

PANTALEÃO, S. M.; MEDEIROS, J. G.; NUM ESMAIA, H. G. \& VIEIRA, J., 1993. Triagem de hemoglobinopatias estruturais em recém-nascidos de João Pessoa - PB. Revista Brasileira de Patologia Clínica, 29:8-13.

PAPADEA, C.; ECKMAN, J. R.; KUEHNERT, R. S. \& PLATT, A. F., 1994. Comparison of liquid and 
dried blood for neonatal hemoglobinopathy screening: Laboratory and programmatic issues. Pediatrics, 93:427-432.

PEDROLLO, E.; HUTZ, M. H. \& SALZANO, F. M., 1990. Alpha thalassemia frequency in newborn children from Porto Alegre, Brazil. Revista Brasileira deGenética, 13:573-581.

ROWLEY, P. T., 1989. Parental receptivity to neonatal sickle cell trait identification. Pediatrics, 83(Sup. 2):891-893.

SALZANO, F. M.; ROCHA, F. J. \& TONDO, C. V., 1968. Hemoglobin types and gene flow in Porto Alegre, Brazil. Acta Genetica et Statistica Medica, 18:449457.

SCHEDLBAUER, L. M. \& PASS, K. A., 1989. Cellulose acetate/ citrate agar electrophoresis of filter paper hemolysates from heel stick. Pediatrics, 83(Sup. 2):839-842.

SERJEANT, G. R., 1999. Sickle cell disease. In: Pediatric Hematology ( J. Lilleyman, I. Hann \& V. Blanchette, ed.), pp. 219-230, 2nd Ed., London: Churchill Livingstone.

SHAFFER, T. J.; LOREY, F.; CUNNINGHAM, G. C.; KLUMPP, C.; VICHINSKY, E. \& LUBIN, B., 1996. Newborn screening for sickle cell disease: 4 years of experience from California's newborn screening program. Journal of Pediatric Hematology/Oncology, 18:36-41.
SOUSA, M. G. F., 1982. Peso ao Nascer: Avaliação do Efeito deVariáveis Biológi cas e Sócio-culturais em uma Amostra de Salvador, Bahia. Dissertação de Mestrado, Salvador: Universidade Federal da Bahia.

SPSS INCORPORATION, 1997. SPSS for Windows. Statistical Package for the Social Sciences. Release 8.0. Chicago: SPSS Inc.

TONDO, C. V. \& SALZANO, F. M., 1962. Abnormal hemoglobins in a brazilian negro population. American Journal of Human Genetics, 14:401-409.

WAJCM AN, H.; BARDAKDJIAN, J. \& DUCROCQ, R., 1993. Structural characterization of abnormal hemoglobins from dried blood specimens in a neonatal screening program. Annales de Biologie Clinique, 50:867-870.

Recebido em 13 de maio de 2000

Versão final reapresentada em 12 de novembro de 2001 Aprovado em 25 de janeiro de 2002 